\title{
Article 31. Assessment and Review
}

The Conference of the Parties serving as the meeting of the Parties to this Protocol shall undertake, four years after the entry into force of this Protocol and thereafter at intervals determined by the Conference of the Parties serving as the meeting of the Parties to this Protocol, an evaluation of the effectiveness of this Protocol.

\section{Overview}

As a specification to the general tasks of the Protocol's governing body, ${ }_{1}$ Article $31^{2}$ requires the COP/MOP to undertake periodic assessments of the effectiveness of the Protocol. Article 31 thus provides an opportunity to identify the need for international guidance or adjustments that may be needed if the evaluation identifies specific areas in which the effectiveness of the Protocol can be improved. ${ }^{3}$ The specific mechanism and modalities for the assessment will have to be decided by the COP/MOP. ${ }^{4}$ The following section will discuss how the assessment and review process will likely function and its linkages with other provisions in the Protocol.

\section{2}

\section{Functions and Links}

Article 31 is modeled after the Cartagena Protocol, ${ }^{5}$ with the only difference that the first review is mandated after four years from entry into force and that following ones will be held at intervals to be determined by the COP/MOP. The Protocol's assessment and review process can be interpreted as institutional supervision of the implementation of the Protocol, collective evaluation of

1 Nagoya Protocol Article 26(4). See this commentary on Article 26, section 2.

2 This provision that was not subject to negotiation: it was first incorporated in the Cali Draft, draft article 24.

3 Mackenzie et al., Explanatory Guide to the Cartagena Protocol, op. cit., 197.

4 Greiber et al., Explanatory Guide, op. cit., 251.

5 Biosafety Protocol Article 35, which reads: 'The Conference of the Parties serving as the meeting of the Parties to this Protocol shall undertake, five years after the entry into force of this Protocol and at least every five years thereafter, an evaluation of the effectiveness of the Protocol, including an assessment of its procedures and annexes.' 
its effectiveness, and as a complementary tool to the multilateral compliance mechanisms and procedures. ${ }^{6}$ As to the latter, the Protocol's governing body is empowered to monitor implementation of the Protocol as a whole, whereas a future compliance committee will most likely focus on compliance by individual Parties ${ }^{7}$ in relation to specific circumstances. Thus, the COP/MOP under its review process will focus on the adequacy of the obligations under the Nagoya Protocol in its entirety, with a view to assessing their aggregate performance in achieving the Protocol's objectives, ${ }^{8}$ rather than the fulfillment of obligations by individual Parties. Nonetheless, the two processes will likely feed into each other: the results of the assessment and review processes may provide information relevant to the work of a future compliance committee, and the latter may also provide information that can contribute to assessment and review. ${ }^{9}$

As in the case of the Biosafety Protocol, the review process is likely to be based in part on the information provided by Parties in their national reports on implementation of the Protocol as well as on other sources of information, ${ }^{10}$ so implementation of Article 31 will rely to a significant extent on compliance by Parties with their reporting obligations. ${ }^{11}$ It can also be expected that submissions from ABs stakeholders, ${ }^{12}$ intergovernmental organizations, ${ }^{13}$ the СвD COP and its subsidiary bodies, notably the Working Group on Article $8(\mathrm{j})$, as well as reports by the Protocol Secretariat mandated to it on an ad hoc basis by the Protocol COP/MOP, will also contribute to the review.

Other provisions of the Protocol have expressly or implicitly made reference to this process. For instance, the review will particularly focus on the effectiveness of measures to ensure compliance with MAT. ${ }^{14}$ In addition,

6 See this commentary on Article 30. This is based, by analogy, on the interpretation of Article 35 of the Biosafety Protocol put forward by Mackenzie et al., Explanatory Guide to the Cartagena Protocol, op. cit., 197.

7 Although note that a future compliance committee under the Protocol may also address compliance issues involving private users and providers: see commentary on Article 30, section 3.3.

8 Bodansky, Art and Craft of International Environmental Law, op. cit., 239.

9 Greiber et al., Explanatory Guide, op. cit., 251.

$10 \quad$ Mackenzie et al., Explanatory Guide to the Cartagena Protocol, op. cit., 197.

11 See this commentary on Article 29.

12 Greiber et al., Explanatory Guide, op. cit., 251.

13 Particularly those involved in international processes that may be mutually supportive with the Protocol: see this commentary on Article 4.

14 Nagoya Protocol Article 18(4). See this commentary on Articles 5, section 5, 6, section 7 and 18. 
Св D Parties have already indicated that the first review under the Protocol will assess the implementation of measures to ensure compliance with domestic ABS requirements related to traditional knowledge, ${ }^{15}$ in light of developments in other relevant international organizations, including WIP $0 .{ }^{16}$

Given the many open-ended provisions of the Protocol, it has also been argued that the assessment and review process will serve to determine whether substantially divergent interpretation among its Parties hinders implementation, and fully assess the need for the Protocol's governing body to provide authoritative interpretation, where needed. ${ }^{17}$ More generally, the assessment and review process will provide an opportunity for the Nagoya Protocol to evolve as a regime in light of lessons learnt in its implementation ${ }^{18}$ and subsequent international developments, which is a common trait among MEAs. ${ }^{19}$

15 See this commentary on Article 16.

16 свD Decision 10/1, paragraph 6. See also this commentary on Article 4, section 3.1.

17 Singh Nijar “An Asian Developing Country's View,” op. cit., 249.

18 Young, “An International Cooperation Perspective," op. cit., 495.

19 Birnie, Boyle and Redgwell, International Law and the Environment, op. cit., 86-87; and Daniel Bodansky and Elliott Diringer, The Evolution of Multilateral Regimes: Implications for Climate Change (Arlington: Pew Center on Global Climate Change, 2010), accessed 30 November 2013, <www.pewclimate.org/docUploads/evolution-multilateral-regimesimplications-climate-change.pdf $>$. 